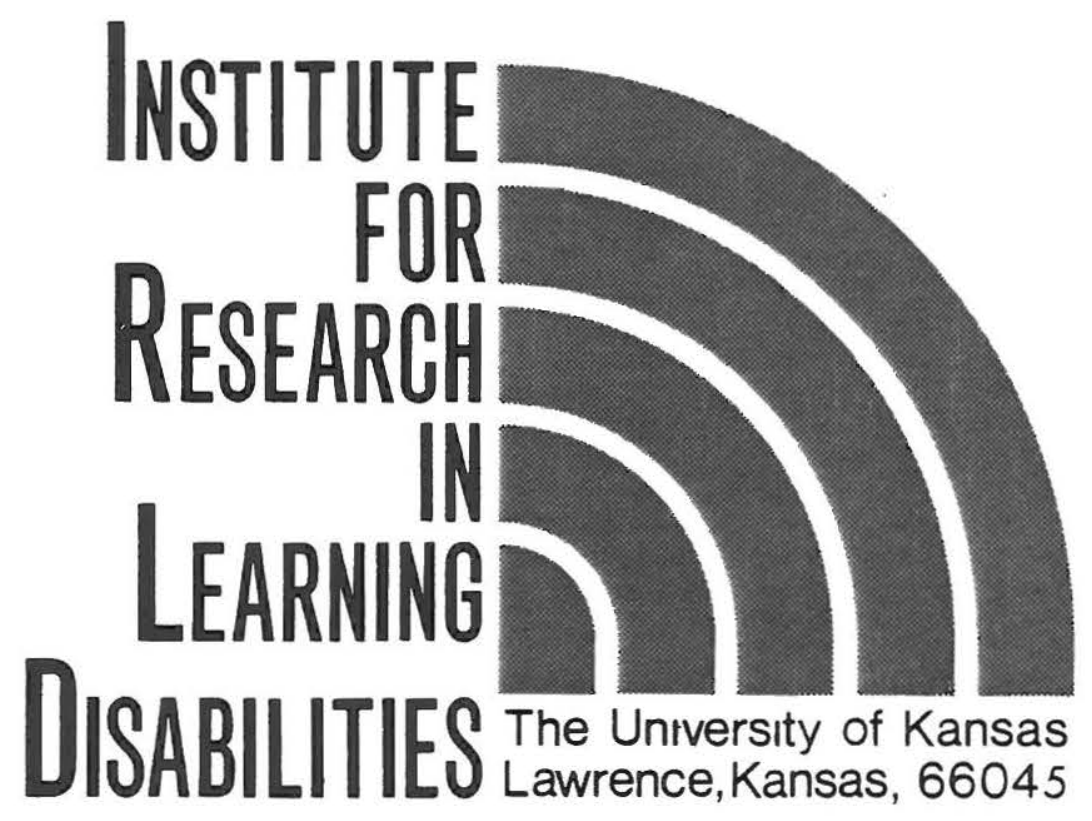

Emphasis on Adolescents and Young Adults

CAREER PREPARATION FOR HANDICAPPED ADOLESCENTS:

A MATTER OF APPROPRIATE EDUCATION

Gary M. Clark

Monograph \#7

January, 1980

This article will appear in Exceptional Education, 1980, 1 (2). 
The University of Kansas Institute for Research in Learning Disabilities is supported by a contract (\#300-77-0494) with the Bureau of Education for the Handicapped, Department of Health, Education, and Welfare, U. S. Office of Education, through Title VI-G of Public Law 91-230. The University of Kansas Institute, a joint research effort involving the Department of Special Education and the Bureau of Child Research, has specified the learning disabled adolescent and young adult as the target population. The major responsibility of the Institute is to develop effective means of identifying learning disabled populations at the secondary level and to construct interventions that will have an effect upon school performance and life adjustment. Many areas of research have been designed to study the problems of LD adolescents and young adults in both school and non-school settings (e.g., employment, juvenile justice, military, etc.)

Co-Directors: Edward L. Meyen

Richard L. Schiefelbusch

Research Coordinator: Donald D. Deshler

Associate Coordinator: Jean B. Schumaker

Institute for Research in Learning Disabilities

The University of Kansas

313 Carruth-0'Leary Hal1

Lawrence, Kansas 66045

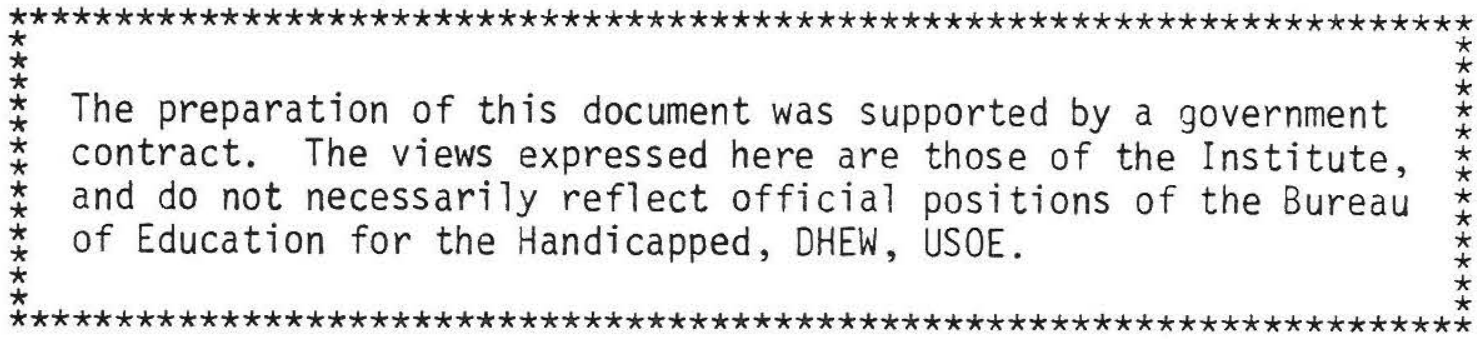




\section{Cooperating Agencies}

Were it not for the cooperation of many agencies in the public and private sector, the research efforts of The University of Kansas Institute for Research in Learning Disabilities could not be conducted. The Institute has maintained an on-going dialogue with participating school districts and agencies to give focus to the research questions and issues that we address as an Institute. We see this dialogue as a means of reducing the gap between research and practice. This communication also allows us to design procedures that: (a) protect the LD adolescent or young adult, (b) disrupt the on-going program as little as possible, and (c) provide appropriate research data.

The majority of our research to this time has been conducted in public school settings in both Kansas and Missouri. School districts in Kansas which are participating in various studies include: United School District (USD) 384, Blue Valley; USD 500, Kansas City; USD 469, Lansing; USD 497, Lawrence; USD 453, Leavenworth; USD 233, 01athe; USD 305, Salina; USD 450, Shawnee Heights; USD 512, Shawnee Mission, USD 464, Tonganoxie; USD 202, Turner; and USD 501, Topeka. Studies are also being conducted in Center School District and the New School for Human Education, Kansas City, Missouri; the School District of St. Joseph, St. Joseph, Missouri; Delta County, Colorado School District; Montrose County, Colorado School District; Elkhart Community Schools, Elkhart, Indiana; and Beaverton School District, Beaverton, Oregon. Many Child Service Demonstration Centers throughout the country have also contributed to our efforts.

Agencies currently participating in research in the juvenile justice system are the Overland Park, Kansas Youth Diversion Project and the Douglas, Johnson, and Leavenworth County, Kansas Juvenile Courts. Other agencies have participated in out-of-school studies-Achievement Place and Penn House of Lawrence, Kansas, Kansas State Industrial Reformatory, Hutchinson, Kansas; the U.S. Military; and the Job Corps. Numerous employers in the public and private sector have also aided us with studies in employment.

While the agencies mentioned above allowed us to contact individuals and supported our efforts, the cooperation of those individuals--LD adolescents and young adults; parents; professionals in education, the criminal justice system, the business community, and the military--have provided the valuable data for our research. This information will assist us in our research endeavors that have the potential of yielding greatest payoff for interventions with the LD adolescent and young adult. 


\section{Abstract}

A complete individualization concept is presented as the avenue to achieve "appropriate education" for handicapped adolescents. Exemplified within the context of the educational goal of career preparation, this concept involves individualization of both content and instructional approach. Career preparation is the attempt to prepare an individual for the course of his/her life rather than simply to prepare him/her for a vocation. The need for career preparation is supported by data which suggest that high school youth lack critical information in the areas of occupational development, daily living skills, and personal-social skills important to one's functioning in today's society. Dr. Clark presents crucial questions which must be asked of today's schools regarding the appropriateness of the content and delivery of secondary school programs for adolescents with handicaps. 


\author{
CAREER PREPARATION FOR HANDICAPPED \\ ADOLESCENTS: A MATTER OF APPROPRIATE EDUCATION \\ Gary M. Clark \\ University of Kansas
}

The essence of what education for handicapped students is about has got to be individualization. On that point, even the most divergent advocates of educational approaches would agree. Or would they? It is likely that they would if they could agree that complete individualization involves both individualization of content (curriculum) as well as individiualization of instructional approach (methodology). Unfortunately, each type of individualization is championed by advocates who think, plan, and act largely independently of the other.

This article is an attempt to make a case for the need for professional educators who are committed to the education of high school level adolescents with handicaps to get back to the complete individualization concept. This position will be based on the assumptions that (a) individualization that relates to both content and instructional approach will lead to "appropriate education" and (b) the message of this position can best be illustrated within the context of the educational goal of career preparation.

It has been proposed elsewhere (Brolin \& Kokaska, 1979; Clark, 1979, 1980; Goldhammer, 1972; Nash \& Agne, 1973; Gysbers \& Moore, 1974) that career preparation is much more than preparation for a job or vocational calling. Without spending unnecessary time and space in arguing the case between semantic integrity and popular usage, the first definition for the word "career" in the Oxford English Dictionary (1961) is "a person's course 
or progress through life." This definition is accepted at face value--the popular connotation of "career" relating to one's life work not withstanding. Hence, career preparation is that formal and informal attempt to make one ready for the course of one's life. This course will involve various roles (family member, neighbor, citizen, worker, etc.), various environments (home, neighborhood and community), and innumerable events (home living, mobility, consumer activities, interpersonal interactions, work activities, etc.).

A legitimate question at this point is, "Why broaden the scope of 'career' beyond what is already a commonly understood synonym for vocation?" Frankly, such an expansion does pose some problems in communication. On the other hand, this broader view focuses on the issue of "appropriate education" in such a way that it demands a response from all of secondary education and not just one discipline or field within education. Educators, particularly at the high school level, must not lose sight of what education is about. When that happens, the outcomes of education become unsatisfactory to students, their families, and to the community.

The accomplishments of millions of unknown individuals who publicly or privately demonstrate their competence, stability, and productivity argue against current criticisms of secondary schools as they exist today. They are products of that system. Educators and professionals concerned with handicapped students, however, must face up to the outcomes of current secondary school programs for exceptional youth who find the current system less than adequate for them. The data on this group are not encouraging at all. When one includes a larger group of school alientated youth who may or may not have identifiable handicaps, the concern for what our high schools are doing increases. 
The following sections provide some research evidence for concerns in the areas of occupational development, daily living skills or adaptive behavior, and personal-social skills--the basic content areas of career preparation.

Occupational Development

Mitchell (1978), in a study that focused on occupational development of seventeen year olds across the nation and which was a part of the National Assessment of Educational Progress, provided some very important data on occupational development. A sample of 34,000 seventeen year olds in school and 1,000 who had graduated or dropped out of school comprised the study. She found many interesting results, some of which are included below:

1. Self perception of abilities

A. Almost twice as many blacks as whites name household skills as something they would like to do better.

B. Males tend to have more confidence in their ability to do things well than do females.

2. Relationships of personal opportunities to occupational requirements

A. Only $2.2 \%$ of the seventeen year olds saw school or academic areas as activities that might be useful for a job.

B. No more than one-fourth of the respondents see the high school counselor among their top five sources of job requirement information.

C. Female aspirations for occupations are highly stereotyped.

3. Personally useful skills 
A. Two-thirds of the in-school seventeen year olds could convert inches to feet; one-third could not. Only $37 \%$ of the out-of-school group could perform the same conversion.

B. On completion of an order blank for purchase of goods, accuracy in written communication was extremely high (91\%-98\%) but about one-fourth of the respondents erred on portions of the order related to computation of cost.

C. Fewer than one-sixth of the respondents can complete sketches of a sphere, a cube, a cylinder, and a pyramid that are acceptable.

D. On. an item presenting a discriminatory policy with the opportunity to suggest a change in the policy, fewer than one-third suggested acceptable changes, and nearly onehalf suggested no change.

E. In writing a job application letter, fewer than half gave such relevant details as education and training, inside address, date, return address, personal facts related to job, reason for wanting the job, or sought contact or interview.

4. Attitudes/values toward work

A. Only $47 \%$ of the seventeen year olds feel that it is possible for a worker to like a repetitive job.

B. "Prestige and status" are cited more than twice as often as "challenge and responsibility," "personal satisfaction," or "opportunity" as reasons for accepting a promotion to a supervisory job. 
C. The most frequently named reason for refusing a promotion to a supervisory job is "too much responsiblity."

The Carnegie Council of Policy Studies in Higher Education (1979) in a study led by Dr. Clark Kerr has estimated that about one-third of today's youth are ill-educated, ill-employed, and ill-equipped to make their way in American society. The Council's report boldly stated that high schools are an alienating experience for thousands of young people. Drop out rates are $23 \%$ overall and $35 \%$ for blacks, $45 \%$ for Hispanics. The school drop out rate for low income white is even higher than that for low income blacks. The Council warns that we are in danger of developing a permanent underclass a self-perpetuating culture of poverty.

While this study reflects a sharper focus on educational opportunity for minority group populations and school and work alienated youths than on exceptional youth, special educators and advocates for the handicapped cannot ignore the Council's position with the argument that special education support services are adequate for handicapped youth. The implication of the Council study is a deep one that strikes at the heart of what constitutes "appropriate education" under P.L. 94-142 and the least restrictive environment concept in the high school. Some of the Council's recommendations reveal its alarm over the career preparation success our high schools are having with up to one-third of its studetns. Keep in mind that these recommendations refer to the basic curriculum options that are available in the mainstream of regular secondary education - the environment held by many to be "least restrictive." Some of the recommendations are:

1. Change the basic structure of high schools by making them smaller or creating more diversity within them. This should involve the creation of full-time speciality schools and flexible scheduling 
that would permit one or two days a week for education-related work or service.

2. Provide federal incentives for moving skills training out of the high school classroom and into the work place or community colleges.

3. Assign to community colleges a greater responsiblility for American youth.

4. Establish a federal-state work-study program for secondary youth aged 16-19, modeled on the present college system.

5. Concentrate on the skills of literacy, numeracy, and good work habits as the basic vocational and academic skills for high school instruction.

\section{Daily Living Skills}

The National Assessment of Educational Progress (1978a) special study on health practices and skills in accident prevention and emergency care in seventeen year olds and adults found that a high percentage of American teenagers and adults know many facts in this area. What they do not know may be more critical. For example, large numbers do not know basic techniques to stop severe bleeding, effective means of administering artificial respiration, or what to do for a victim of a serious burn. Many do not know some basic emergency procedures or accident-prevention measures to heed within the home. Among young adults, most are knowledgeable about alternate ways of preventing pregnancy; many do not know important things about contraception and are not aware of the range of services offered by family planning clinics.

The National Assessment of Educational Progress (1978b) study on social studies and citizenship found that about $40 \%$ of seventeen year olds in school could not satisfactorily explain the growing importance 
of energy resources to the United States. Only 30\% were able to identify the central problem being discussed by a group of speakers. One-third of the seventeen years olds did not know that the legislative branch is responsible for passing laws. When asked if they would try to get an unfair law changed, 41\% say, "Yes, but I don't know what I could do." About one-third acknowledged that they had watched, listened to, or read a news program or newspaper the day previous to their assessment. The National Assessment of Educational Progress (1979) study on the consumer skills of seventeen year old students found that many are short on knowledge of such complicated issues as personal finances, consumer protection and behavior, economics, contractual agreements, and insurance. Most apparent, many teenagers are lacking in the problem-solving mathematics skills needed to make quick, simple calculations in wise consumer transactions. In general, in relation to the four roles of American consumers: concerned citizens, purchasers or spenders, earners and investors, Dr. Roy H. Forbes, director of National Assessment of Educational Progress, stated:

The findings suggest that they are better prepared in some areas than in others, but with performance on an average consumer question at only $57 \%$, there is evidence that the 17 -year olds are not very well prepared for their future consumer responsibilities. (p. 1)

Personal-Social Skills

The area of personal-social skills is extremely broad in scope. Generally, it includes knowledge and skills in personal values and attitudes, self esteem, personal habits, and human relationships. Certainly from the perspective of how adult handicapped have fared in the past, there is a significant body of literature that supports the importance of personalsocial skills (Butler \& Browning, 1974; Cobb, 1972; Goldstein, 1964; and Henrich \& Kriegel, 1961). The more immediate concern is for current high 
school programs in this area, however. Consider the following research results:

-- Steinitz (1976) found that seniors in high school find it difficult to reconcile personal ambition and personal achievement goals with social responsibility. Our culture, and schools which reflect that culture, teach a basic message that self-reliance is a measure of an individual's worth and that people are to be judged on the basis of how hard they try and how much they accomplish.

-- Bachman, O'Malley, and Johnston (1978) reported from their longitudinal study of males from adolescence to adulthood that there was a striking consistency in positive correlations between selfesteem and level of educational attainment. The mean self-esteem scores remained ordered with those who became high school drop outs always lowest in average self-esteem and those who went on to graduate training always highest. More extensive analyses produced findings that suggest that factors such as ability, grades, and family socioeconomic level (all of which predict later socioeconomic development) may also be among the determinants of self-esteem.

-- Leming (1978) reported that knowledge of moral conduct and actual behavior in certain situations differ in high school students and are rationalized by the students in a "get it when you can" philosophy.

-- The U.S. Bureau of the Census (1978) showed a steady increase in juvenile delinquency since 1969, with a 44.6\% increase between 1969 and 1977 for individuals under 18 years of age.

-- Bachman, O'Malley, and Johnston (1978) reported that senior boys admitted to the following behaviors one or more times during the two year period immediately preceding their senior survey: 
Taken part in a group fight 21\%

Involved in a serious fight at school $32 \%$

Damaged school property on purpose 19\%

Involved in shoplifting $36 \%$

Involved in theft under $\$ 50.00 \quad 37 \%$

The sharp decrease in delinquency rates for high school drop outs failed to support the contention that high delinquency rates are a consequence of quitting school. On the contrary, the longitudinal trends suggested that it is more likely that the delinquency contributed to dropping out of school. The investigators suggested the interpretation of these data that failure experiences in school lead to both delinquent behavior and dropping out of school.

The Planned Parenthood Federation of America (1977) has reported data that may support some of the National Assessment (1978a) findings on lack of knowledge regarding contraception. A Federation information piece stated that:

-- American teenage childbearing rates are among the highest in the world.

-- One-fifth of all births in the United States are to teenagers.

-- Of the young people between the ages of 15 to $19,52 \%$ are estimated

to have had sexual intercourse.

It is possible that these data may relate as much to personal-social values, attitudes, and behavior as to knowledge or lack of knowledge in this area, Either way, the implication for the high school's potential role is clear. The Is sue in Focus

If America's high schools are still dedicated to their early goals of civic responsibility, occupational adequacy, worthy home membership, and wise use of leisure time, some questions must be asked: 
"Are the goals espoused in the past relevant for today?"

"If the goals are relevant, are the research data presented above pertinent to today's high schools' success in meeting them?"

"If the research evidence is relevant to the goals, is it sufficient

to question the appropriateness of current high school programs?"

"If the research evidence is sufficient to challenge the appropriateness

of high schools today, is the problem of appropriateness primarily a

result of inappropriate curriculum and/or of inappropriate and, thus, ineffective instruction?"

"Can the determination of "appropriate education" by means of an individualized educational program for any exceptional youth be made independently of any of the concerns raised in the questions above?"

These questions are not meant to be rhetorical. They are meant to bring into focus the issue of the appropriateness of a majority of today's high schools' programs. Responses to each question, whether negative or affirmative, should lead to some type of action response. If inappropriateness of curriculum is seen as the heart of the problem, curricular reforms should be planned and put into effect. If inappropriateness of instructional delivery is viewed as the Achilles' heel, then effective instructional strategies and methodologies must be identified and made a part of the teaching process. If both are seen as inappropriate to some degree, then both require some action.

Decisions as to how to effect changes in a high school program for high risk or vulnerable groups are difficult to make and even more difficult to enact. An even more challenging task is the extension of that decision-making process down to high risk or vulnerable individuals. 
It is at that point that individual curriculum content needs and unique learning styles and approaches become the essence of what education is about for that individual. The following assumptions about educational programming for handicapped adolescents are presented as guidelines for complete individualization:

1. The higher one goes up the grade-level hierarchy, the greater the discrepancies among students in intel lectual functioning, academic achievement, social experience, and personal maturity.

2. The higher one goes up the grade-level hierarchy, the greater the desire and/or demand by students for school to be related to immediate and near-future needs.

3. The higher one goes up the grade-level hierarchy, the greater the need by students to have greater identification and personal interaction with one or two significant adults who, by proximity and commitment, are readily available for guidance and counseling.

4. A democratic philosophy of education and a realistic philosophy of normalization do not dictate that all persons have the same educational experiences. (Clark, 1975, p. 2).

Career preparation in its broadest perspective is obviously a valued educational goal of this writer for handicapped youth. As a goal around which content and instructional approach can be individualized, it speaks to the issue of usefulness--to the point of alienation of educators who are concerned about academic standards and minimum competencies. Marland (1974, p. 13) quotes Alfred North Whitehead as saying: "Pedants sneer at an education that is useful, but if it is not useful, what is it?" Without apology, that view is supported here. But useful content offerings are not sufficient. That content must be 
taught effectively.

For whatever reasons, we educators have too frequently lost sight of personal outcomes in designing high school curricula and organizing high school programs. Now that handicapped adolescents are increasingly being identified and scheduled into regular high school programs, we must challenge the appropriateness of their content and their delivery. If the challenge is satisfied, then we can proceed; if not, there is little justification for continuing current practices. 


\section{References}

Bachman, J. G., O'Malley, P. M., \& Johnston, J. Youth in transition, Volume VI. Ann Arbor, Michigan: Institute for Social Research, 1978.

Brol in, D. E., \& Kokaska, C. J. Career education for exceptional children and youth. Columbus, Ohio: Charles E. Merrill, 1979.

Butler, A. J., \& Browning, P. L. Predictive studies on rehabilitation outcome with the retarded. In P. L. Browning (Ed.), Mental retardation: Rehabilitation and counseling. Springfield, Illinois: C.C. Thomas, 1974.

Carnegie Council of Policy Studies in Higher Education. Giving youth a better chance: Options for education, work and service. San Francisco: Jossey-Bass, 1979.

Clark, G. M. Career education for the handicapped: Current perspectives for teachers. Boothwyn, Pennsylvania: Educational Resources Center, 1980.

Clark, G. M. Career education for the handicapped child in the elementary classroom. Denver: Love Publishing, 1979.

Clark, G. M. Mainstreaming for the secondary educable mentally retarded:

It is defensible? Focus on Exceptional Children, 1975, $\underline{7}$ (2), 1-5.

Cobb, H. V. The forecast of fulfillment: A review of research on predictive assessment of the adult retarded for social and vocational adjustment. New York: Teachers College Press, 1972.

Goldhammer, K. A. A careers curriculum. In K. Goldhammer \& R. E. Taylor (Eds.), Career education: perspective and promise. Columbus, Ohio: Charles E. Herri1l, 1972. 
Goldstein, H. Social and occupational adjustment. In H. A. Stevens \&

R. F. Heber (Eds.), Research in mental retardation. Chicago:

University of Chicago Press, 1964.

Gysbers, N. C., \& Moore, E. J. Career guidance, counseling and placement:

Elements of an illustrative program guide. Columbia, Missouri: Career Guidance, Counseling and Placement Project, University of MissouriColumbia, 1974.

Henrich, E., \& Kriegel, L. Experiments in survival. New York: Association for the Aid of Crippled Children, 1961.

Leming, J. S. Cheating behavior, situational influence, and moral development. Journal of Educational Research, 1978, 71, 214-217.

Marland, S. P., Jr. Career education: A proposal for reform. New York: McGraw-Hil1 , 1974.

Mitchel1, A. M. Career development needs of seventeen year olds: How to improve career development programs. Monograph of the National Vocational Guidance Association and the Association for Measurement and Evaluation in Guidance (divisions of American Personnel and Guidance Association). Washington, D. C., 1978.

Nash, R. J., \& Agne, R. M. Career education: Earning a living or living a life. Phi Delta Kappan, 1973, 54, 373-378.

National Assessment of Educational Progress. Are 17-year-olds prepared? Doors open to 'real' consumer world. NAEP Newsletter, 1979, 12 (3), $1,3-4$.

National Assessment of Educational Progress. It's what you don't know that 'hurts'. NAEP Newsletter, 1978a, 11(5), 1, 3. National Assessment of Educational Progress. Wrap-up: Social studies/ citizenship. Spotlight from the NAEP Newsletter, 1978b, 11(5), 1-2. 
Planned Parenthood Federation of America. Brochure on need for planned parenthood education, 1977.

Steinitz, V. "People need help, but people take advantage": The dilemma of social responsibility for upwardly mobile youth. Youth and Society, $1976, \underline{7}(4), 399-438$.

The Oxford English Dictionary, Volume II. London: Oxford University Press, 1961.

U. S. Bureau of the Census. Statistical Abstract of the United States: 1978 (99th Edition). Washington, D. C., 1978. 